\title{
Improving Communication Between Doctors and Breast Cancer Patients
}

\author{
Moira Stewart, $P b D^{1}$ \\ Judith Belle Brown, $P b D^{1}$ \\ Joanne Hammerton, MSc ${ }^{2}$ \\ Allan Donner, $\mathrm{PbD}^{3}$ \\ Alan Gavin, MSW $W^{4,5}$ \\ Ronald L. Holliday, MD, FRCS $(C)^{6,7}$ \\ Tim Whelan, $B M, B C b^{8}$ \\ Ken Leslie, MD, FRCS $(C)^{6}$ \\ Irene Coben, $M D^{9}$ \\ Wayne Weston, MD \\ Tom Freeman, $M D^{9}$ \\ ${ }^{1}$ Centre for Studies in Family Medicine \\ The University of Western Ontario, Lon- \\ don, Ontario, Canada \\ ${ }^{2}$ School of Nursing, The University of \\ Western Ontario, London, Ontario, Canada \\ ${ }^{3}$ Department of Epidemiology and Biosta- \\ tistics, The University of Western Ontario, \\ London, Ontario, Canada \\ ${ }^{4}$ London Regional Cancer Centre, London, \\ Ontario, Canada \\ ${ }^{5}$ Department of Social Work, St. Joseph's \\ Healthcare Hamilton, Hamilton, Ontario, \\ Canada \\ ${ }^{6}$ Department of Surgery, The University of \\ Western Ontario, London, Ontario, Canada \\ ${ }^{7}$ Division of General Surgery, Victoria \\ Campus, London Health Sciences Centre, \\ London, Ontario, Canada \\ ${ }^{8}$ Department of Medicine, McMaster Uni- \\ versity and Director, Supportive Cancer \\ Care Research Unit, Juravinski Cancer \\ Centre (formerly Hamilton Regional Can- \\ cer Centre), Hamilton, Ontario, Canada \\ ${ }^{9}$ Department of Family Medicine, The \\ University of Western Ontario, London, \\ Ontario, Canada \\ Conflicts of interest: none reported
}

\section{CORRESPONDING AUTHOR}

Moira Stewart, PhD

Centre for Studies in Family Medicine 245-100 Collip Circle, UWO Research Park London, ON, N6G 4X8, Canada moira@uwo.ca

\begin{abstract}
PURPOSE We wanted to assess the effectiveness of intensive education for physicians compared with a traditional session on communicating with breast cancer patients.

METHODS A randomized controlled trial was conducted in practices in London, Hamilton, and Toronto, Canada, with 17 family physicians, 16 surgeons, and 18 oncologists, and with 102 patients of the surgeons and oncologists. Doctors were randomized to 1 of 2 continuing education approaches: a traditional 2-hour version (control group), or a new 6-hour intensive version including exploring the patients' perspectives and reviewing videotapes and receiving feedback (intervention group). Communication behavior of the physicians was measured objectively both before and after the intervention. As well, 4 postintervention patient outcomes were measured, by design only for surgeons and oncologists: patientcenterdness of the visit, satisfaction, psychological distress, and feeling better.
\end{abstract}

RESULTS No significant differences were found on the communication score of the intervention vs the control physicians when controlling for preintervention communication scores. Intervention family physicians, however, had significantly higher communication subscores than control family physicians. Also, patients of the intervention surgeons and oncologists were significantly more satisfied (scores of 82.06 vs $77.78, P=.03$ ) and felt better $(88.2 \%$ vs $70.6 \%, P=.02$ ) than patients of the control surgeons and oncologists when controlling for covariates and adjusting for clustering within doctor.

CONCLUSIONS The continuing medical education intervention was effective in terms of some but not all physician and patient outcomes.

Ann Fam Med 2007;5:387-394. DOI: 10.1370/afm.721.

\section{INTRODUCTION}

$\mathrm{P}$ atient-physician communication is of intense interest in our consumer age because major problems have been documented ${ }^{1,2}$ and unfavorable outcomes have been implicated, eg, patient dissatisfaction, ${ }^{3}$ lack of patient adherence, ${ }_{1}^{4}$ poorer self-reported health, ${ }^{5}$ physician satisfaction, ${ }^{6}$ and malpractice claims. ${ }^{7}$ Whereas programs to improve communication are common in undergraduate medical programs and residency programs ${ }^{8-10}$ continuing medical education programs are less common. ${ }^{11,12}$ Notable exceptions include studies that evaluate communication in terms of improved outcomes. Although research designs have evolved from nonrandomized studies with self-report outcomes ${ }^{13,14}$ to randomized trials with communication behaviors measured objectively $y^{7,15}$ and with patient outcome measures, ${ }^{16}$ only slightly more than one-half of the studies were able to show an impact on patient health outcomes. ${ }^{5,17}$ The education programs have varied in length (from 4 hours to 3 days). Few studies incorporated varied teaching approaches (despite the finding that multiple interventions are more effective), ${ }_{1}^{18}$ and few were based on conceptual frameworks of good communication or on the expressed needs of patients.

We therefore designed a new continuing medical education (CME) 
program of feasible length ( 6 hours), using multiple approaches and based on expressed needs of patients and a recognized conceptual framework. ${ }^{19}$ We tested the hypothesis that the new CME would change verbal communication of surgeons, oncologists, and family physicians, and that it would also influence breast cancer patients' perceptions of both the patient-physician interaction and their own health. We conducted a randomized controlled trial of 2 CME approaches: (1) a traditional 2-hour CME showing a videotaped consultation, which was then discussed; and (2) a new stateof-the-art 6-hour CME including the above plus 2 new elements: a discussion of the patients' perspectives, and a videotape review with individual feedback.

\section{METHODS}

\section{Participants}

This study was approved by the Human Subjects Review Committee of The University of Western Ontario. We recruited 51 interested family physicians $(n=17)$, general surgeons $(n=16)$, and oncologists $(n=18)$ in Southern Ontario, Canada. Recruitment occurred through letters of information and personal telephone contact by the respective family physician, surgery, and oncology coinvestigators and was guided by the approach outlined in Borgiel et al. ${ }^{20}$ The 51 physicians were randomized to 1 of the $2 \mathrm{CME}$ approaches, with each physician providing outcome data on communication. By design, only breast cancer patients of surgeons and oncologists provided patientrelated outcome data, because family physicians and surgical residents care for so few eligible breast cancer patients at any time. Eligible patients were older than 18 years and within 1 year of the diagnosis of breast cancer or within 1 year of the diagnosis of a recurrence of breast cancer. Patients were excluded if they were too ill or disabled to answer the questions at the entry interview, unable to understand simple English instructions, or cognitively impaired in the opinion of the physician. Eligible patients (10 per doctor) were asked at the time of a visit to their surgeon or oncologist to participate, and consent was obtained to fill out a questionnaire immediately after the visit and mail it back.

\section{Interventions}

\section{State-of-the-Art CME}

The state-of-the-art CME program was developed on the basis of the qualitative findings from our previous study, ${ }^{21}$ our conceptual framework for patientcentered communication, ${ }^{22}$ the commu- nication and CME literature, and the expertise of an educator (W.W.). The program incorporated the principles of adult education ${ }^{23,24}$ and experiential learning $^{25-28}$ and contained 5 key elements: (1) literature-a description of the benefits of improved patient-physician communication for both patients and doctors; (2) physicians' perspectives-participating physicians ventilated about barriers to and shared solutions for effective communication, (3) patients' perspectives-first, a videotape of the findings of the qualitative study of breast cancer patients' issues regarding communication, and second, breast cancer survivors in person talking about their own concerns; (4) video demonstration - a scripted "not-so-good" and "better" interaction between a breast cancer patient/actress and physician; and (5) practice with standardized patients and videotape review with feedback. The CME program was developed during an 18 -month period that included formal pretests with evaluation ${ }^{29,30}$ and was facilitated by a communication educator and clinician. The CME program is outlined in Table 1.

\section{Traditional CME}

The control group experienced a conventional CME session on communicating with breast cancer patients, which included a 2-hour small-group discussion triggered by a videotaped encounter between a physician and a breast cancer standardized patient.

\section{Objectives}

We hypothesized that, compared with the control group, the group of physicians attending the 6-hour intervention CME session would receive higher scores on an objective communication measure controlling for preprogram communication scores. We also hypothesized that breast cancer patients of the oncologists and surgeons would have higher scores on perceptions of patient-centered communication, be more satisfied with the physician's information-giving and interpersonal skills, experience less psychological distress, and feel

\begin{tabular}{lcc}
\hline Table 1. Continuing Medical Education Program Course Outlines \\
\hline Course Element & $\begin{array}{c}\text { Intervention } \\
\text { State-of-the-Art } \\
\text { Course }\end{array}$ & $\begin{array}{c}\text { Control } \\
\text { Traditional Course }\end{array}$ \\
\hline Length, hr & 6 & 2 \\
$\begin{array}{l}\text { Literature on the benefits of patient- } \\
\text { physician communication }\end{array}$ & $\checkmark$ & $\checkmark$ \\
Physicians' perspective & $\checkmark$ & $\times$ \\
$\begin{array}{l}\text { Patients' perspective } \\
\text { Video demonstration and discussion }\end{array}$ & $\checkmark$ & $\times$ \\
Two interviews with standardized & $\checkmark$ & \\
patients and subsequent video- & $\checkmark$ & \\
tape review and feedback & & \\
\hline
\end{tabular}


better after the visit with the doctor, after controlling for confounding variables and adjusting for clustering effects within doctors.

\section{Outcomes}

The objective Patient-Centred Communication Measure $^{31}$ was adapted for visits regarding breast cancer. The original measure was used to code and score recorded verbal communication, was reliable (interrater agreements of $74 \%$ to $94 \%$ and intrarater correlation of 0.73 ) and valid (correlation with a global score, 0.85$),{ }^{31}$ and it had been used in 2 previous studies. ${ }^{32,33}$ The original measure was adapted by creating 2 subscores: 1 subscore on validation of the patients' expressed experiences, and 1 subscore on explicit support expressed by the physician. Subscores were further regrouped into the 4 major themes identified in our qualitative study (building relationships, sharing information, creating an experience of control, and mastering the whole person experience). ${ }^{21}$ The total score and each subscore ranged from 0 to 100 .

Also, 4 patient outcomes were collected through questionnaires: (1) patient perceptions of patient-centeredness were assessed by a valid 12 -item questionnaire based on Henbest et $\mathrm{al}^{33,34}$; (2) the patients' satisfaction with doctors' information-giving and interpersonal skills was assessed by the valid and reliable 18 -item Cancer Diagnostic Interview Scale (CDIS) ${ }^{35}$; (3) patients' psychological distress was assessed by the 51-item Brief Symptom Inventory, which addresses 3 dimensions particularly relevant for breast cancer patients (anxiety, depression, and hostility) and correlates highly with the benchmark SCL-90 (Symptom Checklist) ${ }^{36}$; and (4) whether patients felt better after a visit to the doctor was assessed by a single validated item. ${ }^{37}$

\section{Data Collection}

\section{Patient-Centered Communication Scores}

Before the CME session, data were collected in the physicians' offices by recording visits with 2 announced standardized patients and scored, resulting in 1 average pre-CME score per physician. After the CME session, data scores from the audiotapes of visits with 2 more announced standardized patients were averaged to create each physician's post-CME communication score.

Four different case scenarios for standardized patients were developed for use in the pre-CME and post-CME visits. Each physician saw all 4 cases, which were randomly ordered for each physician so that there was no before-after bias in the level of difficulty. Appointments were arranged through the physician's office staff during regular patient hours; a brief case history was provided, including mock biopsy, sono- gram, and mammogram reports specific to each case scenario and designed to create an aura of authenticity.

Two well-trained raters coded and scored the recorded visits. The timing of the audiotape (pre-CME or post-CME) and the group allocation of the physician were concealed from the raters.

\section{Patient Outcomes}

Eligible, consecutive real patients completed questionnaires after their visit with their surgeon or oncologist and mailed them back within 1 month of the intervention.

\section{Sample Size}

To detect a clinically significant difference of 10 points (with standard deviations at 10.1) on the objective communication score with $80 \%$ power and $\alpha=.05$ (2-sided), 32 doctors were the minimum required. ${ }^{38}$ To estimate the number of patients needed for the 3 continuous patient outcomes, standardized effect sizes of 0.6 were deemed adequate. Fifty-one patients per group were required to permit analysis adjusting for clustering of patients within doctor.

\section{Randomization}

Randomization was done by the project coordinator. Physicians were recruited in blocks by specialty category and city. After the whole block of physicians had been recruited, the physicians were allocated using a random number table. Although the doctors and the teachers of the CME could not be masked, the audiotape coder, the standardized patients, and the real patients were masked to the doctors' allocation.

\section{Statistical Methods}

We used ANCOVA to test for differences between the 2 groups on the objective communication measure controlling for the corresponding baseline objective communication score; the unit of analysis was the doctor. Mixed model linear regression was used to test for differences between the patients of the 2 groups of doctors on the 3 continuous patient outcome variables. The clustering of patients within doctor was adjusted for using SAS "procedure mixed." As well, to increase precision, 2 covariates were selected for adjustment on the basis of their potential to affect the outcome and the clinical significance of their differences between the intervention and control group: patient education level (dichotomized at secondary school completion) and medical conditions (expressed as mean number). Mixed model logistic regression was used for the one dichotomous patient outcome (feeling better), adjusting for clustering and the identical 2 covariates, using generalized estimating equations. ${ }^{39}$ 


\section{Figure 1. Diagram of participants in the study.}

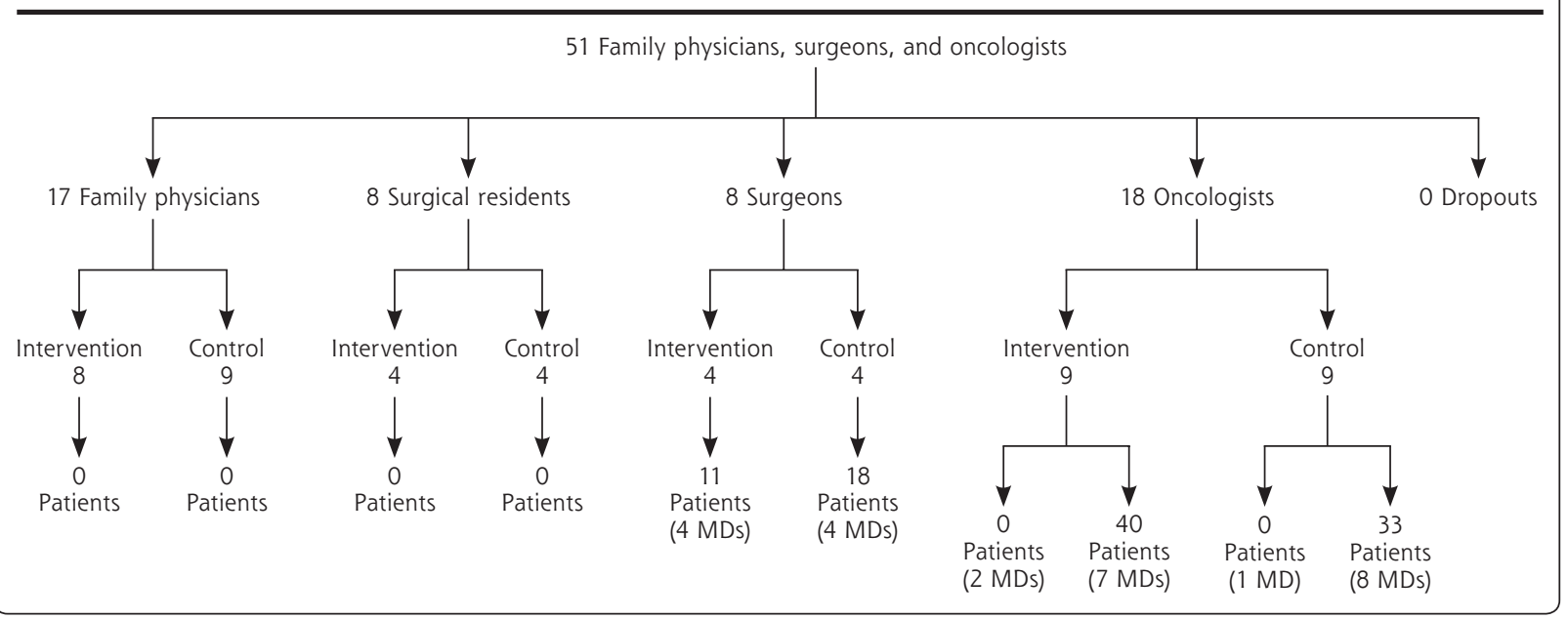

\section{RESULTS}

Fifty-one physicians and 102 patients participated in the study. Figure 1 shows the flow of participants: (1) family physicians, oncologists, and surgeons who were approached, entered into the trial, randomized, and completed the trial (approximately $40 \%$ of doctors approached agreed to participate, and all 51 who agreed completed both the intervention and the doctor measures); (2) patients of oncologists and surgeons who were approached and completed the questionnaire. By design, patient data were not sought for family physicians and surgical residents. The 23 surgeons and oncologists who collected patient data achieved a $44.3 \%$ patient response rate (as a result of a combination of doctors' failure to distribute and patients' failure to mail back the questionnaire).

Responding patients were more likely from oncologists $48.7 \%$ than surgeons $36.3 \%$, but they were almost evenly split between intervention (46.4\%) and control (42.5\%) group.

Baseline characteristics of the physicians are shown in Table 2 . There were no substantive or significant differences between intervention and control physicians. Patient characteristics were similar in the 2 groups with respect to marital status (52\% married vs $48 \%$ ), mean age ( 58.4 vs 59.5 years), mean scores on preference for information (7.6 vs 6.9), and involvement in decisions (2.7 vs 2.6). Differences were observed with respect to education (intervention group 54\% with high school or less vs $46 \%$ in the control group) and mean number of medical conditions (1.1 vs 1.4 ).

The postintervention objective communication scores of physicians did not differ significantly over-
Table 2. Comparison of the Characteristics of the Intervention and Control Groups

\begin{tabular}{lcc}
\hline & $\begin{array}{c}\text { Intervention } \\
\text { Group } \\
(\mathbf{n}=\mathbf{2 5})\end{array}$ & $\begin{array}{c}\text { Control Group } \\
\text { (n = 26) }\end{array}$ \\
\hline Characteristic & & \\
\hline Type of doctor, No. (\%) & $9(34)$ \\
Family physician & $8(32)$ & $8(30)$ \\
Surgeon & $8(32)$ & $9(34)$ \\
Oncologist & $9(36)$ & $26(100)$ \\
Total & $25(100)$ & $18(69)$ \\
Sex, No. (\%) & & $8(30)$ \\
Male & $16(64)$ & $26(100)$ \\
Female & $9(36)$ & $12(46)$ \\
Total & $25(100)$ & $14(53)$ \\
Year of graduation, No. (\%) & & $26(100)$ \\
Before 1986 & $13(52)$ & $13(52)$ \\
1986 or after & $12(48)$ & $12(48)$ \\
Total & $25(100)$ & $25(100)^{*}$ \\
Communication courses, No. (\%) & & $70.4(11.94)$, \\
Yes & $11(44)$ & \\
No & $14(56)$ & \\
Total & $25(100)$ & \\
Baseline objective: communication & $74.6(12.10)$, & \\
scores, mean (SD), 95\% Cl & $69.61-79.60$ & \\
\hline *ne control group doctor did not answer this question. & \\
\hline
\end{tabular}


ing support, $77.8 \%$ vs $22.2 \%)_{i}$ (2) information sharing (the physicians describing and the patients responding, score of 86.3 vs 66.3); (3) exploring whole person

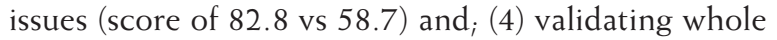
person issues (score of 77.0 vs 49.1 ). Further inspection of the data showed that a floor-effect could not be responsible for these differences in the family physicians relative to the other medical disciplines.

Of the 4 hypotheses regarding outcome variables measured on patients of surgeons and oncologists (Table 4), 2 were supported (patient satisfaction and the patients feeling better). Table 5 shows detail of the statistics for 1 of the 4 patient outcomes, patient satisfaction.

\section{DISCUSSION}

The trial found that the state-of-the-art CME did not improve overall objective communication scores but was related to patient satisfaction and feeling better. Also, it did improve family physicians' objective communication subscores but not those of the surgeons and oncologists. These seemingly contradictory results lead one to speculate about a number of alternative explanations. One explanation may be the relative appropriateness of the different parts of the CME program for the different types of doctors. Perhaps the family doctors were more accepting of and responsive to the CME program because of the greater frequency of videotapeand-feedback training in residencies in family medicine as compared with residencies in surgery and oncology. Also, perhaps the part of the program that introduced the patients' perspective (where real patients told their story, expressed their feelings, and explained their issues) was effective in raising the oncologists' and surgeons' consciousness, thereby altering their visits with patients in ways that patients noticed.

\begin{tabular}{|c|c|c|c|c|c|}
\hline \multirow[b]{2}{*}{ Family Physicians } & \multicolumn{2}{|c|}{$\begin{array}{l}\text { Intervention } \\
\quad(n=8)\end{array}$} & \multicolumn{2}{|c|}{$\begin{array}{l}\text { Control } \\
(n=9)\end{array}$} & \multirow[b]{2}{*}{$P$ Value } \\
\hline & $\begin{array}{l}\text { Mean Score } \\
\text { (SD) }\end{array}$ & $\mathrm{Cl}$ & $\begin{array}{l}\text { Mean Score } \\
\text { (SD) }\end{array}$ & $\mathrm{Cl}$ & \\
\hline \multicolumn{6}{|l|}{ Building relationships } \\
\hline Exploration of illness experience & $65.0(5.07)$ & $57.85-71.68$ & $56.3(11.44)$ & $50.04-63.08$ & .09 \\
\hline Validation of patients' illness experience & $79.1(14.78)$ & $67.54-91.39$ & $71.7(15.48)$ & $60.13-82.59$ & .31 \\
\hline Offering support, \%* & $77.8(\mathrm{n} / \mathrm{a})$ & & $22.2(\mathrm{n} / \mathrm{a})$ & & .02 \\
\hline \multicolumn{6}{|l|}{ Sharing information } \\
\hline $\begin{array}{l}\text { Physician description and patient } \\
\text { response }\end{array}$ & $86.3(18.29)$ & 71.78-101.56 & $66.3(19.23)$ & $51.93-79.96$ & .05 \\
\hline \multicolumn{6}{|l|}{ Creating an experience of control } \\
\hline Mutual discussion of management plan & $68.8(45.81)$ & $39.13-98.36$ & $62.2(31.26)$ & $34.30-90.15$ & .74 \\
\hline \multicolumn{6}{|l|}{ Mastering the whole person experience } \\
\hline Exploration of whole person issues & $82.8(9.81)$ & $69.12-92.34$ & $58.7(18.33)$ & $49.60-71.39$ & .02 \\
\hline Validation of whole person issues & $77.0(15.97)$ & $58.04-93.43$ & $49.1(26.31)$ & $33.61-66.86$ & .05 \\
\hline Total score & $75.6(14.73)$ & $62.90-84.99$ & $60.2(15.27)$ & $51.29-72.07$ & .11 \\
\hline
\end{tabular}

Note: Analysis controlling for baseline objective communication score. Total score and each subscore ranged from 0 to 100 .

* The support score is the only one expressed as a percentage, not a continuous variable.

Table 4. Multivariable Analysis of the 4 Patient Outcome Measures in Relation to Doctor's Intervention Status $(\mathrm{n}=102)$

\begin{tabular}{|c|c|c|c|c|}
\hline Outcome Variable & $\begin{array}{l}\text { Intervention } \\
\text { Group }\end{array}$ & $\begin{array}{l}\text { Control } \\
\text { Group }\end{array}$ & Coefficient/SE & $P$ Value \\
\hline Patient perception of patient-centeredness, mean score (SD) ${ }^{* \dagger}$ & $3.28(0.49)$ & $3.14(0.49)$ & -1.02 & .32 \\
\hline $\begin{array}{l}\text { Patient satisfaction with doctor's information-giving and inter- } \\
\text { personal skills, mean score }(S D)^{*+}\end{array}$ & $82.06(5.80)$ & $77.78(8.07)$ & -2.28 & .03 \\
\hline Patients' psychological distress, mean score $(S D)^{* \dagger}$ & $0.40(0.40)$ & $0.46(0.38)$ & 1.18 & .25 \\
\hline Patient perception of well-being (worse/same vs better), \%‡ & 88.2 & 70.6 & -2.39 & .02 \\
\hline
\end{tabular}




\begin{tabular}{|c|c|c|c|c|}
\hline Outcome: Satisfaction & Coefficient & SE & Coefficient/SE & $P$ Value \\
\hline \multicolumn{5}{|l|}{ Independent variables } \\
\hline Group & -3.92 & 1.72 & -2.28 & .03 \\
\hline Education & 0.65 & 1.39 & 0.47 & .65 \\
\hline \multirow[t]{2}{*}{ No. of medical conditions } & 0.43 & 0.56 & 0.77 & .45 \\
\hline & $\begin{array}{l}\text { Mean Score } \\
\text { (SD) }\end{array}$ & & & \\
\hline \multicolumn{5}{|l|}{$\begin{array}{l}\text { Mean level of satisfaction } \\
\text { by group }\end{array}$} \\
\hline Intervention & $82.06(5.80)$ & & & \\
\hline Control & $77.78(8.07)$ & & & \\
\hline
\end{tabular}

Note: Analysis controlling for patients' education and number of medical conditions and adjusting for clustering within doctor.

If the latter is the correct interpretation, it is worth describing more fully the part of the CME program that addressed the patients' perspective. The doctors were prepared for the patients' perspective by first being invited to express their own perspective, including perceived barriers and facilitators in communicating with breast cancer patients. Next, when the physicians were ready to turn to the patients' perspective, they viewed a video of breast cancer survivors explaining the findings of our formal qualitative study. Finally, 2 breast cancer survivors came into the seminar room and told their stories briefly and answered questions. The reality of the patients' palpable anxiety and fear was inescapable.

There is a second explanation for why the state-ofthe-art CME improved family physicians' communication scores but not surgeons' and oncologists' scores. Although the family physicians did not work in the same practice, the surgeons, surgical residents and oncologists did, thereby opening the door to possible contamination, mitigating against finding differences between the state-of-the art CME and the traditional CME group.

A third explanation for the contradictory finding that intervention group surgeons and oncologists did not change their behavior (on the objective communication measure) but their patients reported higher satisfaction and felt better is that the objective communication measure missed some crucial component of what was taught and learned. For example, this measure does not take into account nonverbal communication. A previous study by the authors suggested that patient perceptions, not the objective measure, correlated with patient health outcomes (including recovery from symptoms and SF-36 [Short Form] self-rated health), implying that patients discerned important dimensions of communication not captured by the objective measure ${ }^{33}$ As well, the objective measure was developed in family medicine and, although it was adapted for this study of breast cancer patients, it might not be sensitive enough to behaviors of surgeons and oncologists.

A strength of the current study is that the objective communication measure was obtained both before and after the intervention. Communication measurement raises other issues. First, whereas audiotape studies of real patients typically use 10 patients per doctor, most studies of standardized patients analyze 1 patient per doctor, ${ }_{1}^{40,41}$ claiming that standardized patients reduce variability (of patient problem and doctor behavior). We attempted to improve reliability by using 2 patients, as did Epstein et al. ${ }^{42}$ Any possible misclassification will lead to a more conservative estimate. Second, if a Hawthorne effect occurred because the standardized patients were announced, it would be equal in the intervention and control groups, and thus not threaten internal validity; but it may limit the study's generalizability to real-world patient visits. Evidence shows almost negligible Hawthorne effect, however, that is, negligible change in correlates of communication scores when doctors know they are being studied compared with when they do not: Korsch et al's seminal study ${ }^{43}$ comparing doctors audiotaped with those not, and Epstein et a $\mathrm{a}^{42}$ comparing detected and undetected standardized patients.

This study contributes to the growing body of data on the "dose-response" of communication education and indicates some impact of a shorter course than previously reported, ie, 6 hours in the current study vs 2.5 days ${ }^{7}$ and 3 days. ${ }^{16}$ Our program and these 2 longer programs included similar elements, such as physicians expressing their problems, and the video review with individual feedback. A unique element in our program was the patient perspective (videotaped findings of the qualitative study and breast cancer survivors in the seminar room).

The results of this study must be interpreted cautiously given that multiple tests were performed and some differences observed may have been due to chance. Even so, the robust magnitude of the differences somewhat weigh against this possibility. Other limitations include limited generalizability of the study (the sample of physicians was not randomly selected); fewer than one-half of the doctors approached agreed 
and completed the trial; and similarly, the patient sample was not representative in that only $44.3 \%$ of eligible patients completed the questionnaire. Finally generalizability of the CME itself was limited because it was co-conducted by an experienced communication educator and highly motivated clinicians.

Breast cancer patients were more satisfied and felt better after visits with surgeons and oncologists who had participated in a 6-hour CME on communication as compared with patients of control group physicians. Despite this finding, the surgeons and oncologists did not change their communication behavior as reflected by the objective measure, although the family doctors did. These data suggest that the new intensive 6-hour CME is effective but with possibly different impact among different types of doctors.

To read or post commentaries in response to this article, see it online at http://www.annfammed.org/cgi/content/full/5/5/387.

Submitted September 13, 2006; submitted, revised, April 4, 2007; accepted April 9, 2007.

Key words: Breast cancer; patient-doctor relationship; communication

Versions of this paper were presented at the North American Primary Care Research Group 28th Annual Meeting, Amelia Island, Florida, November 2000; Health and Communication for Health Professionals, Educators and Researchers, Barcelona, Spain, September 2000; Trillium Primary Care Research Conference, Hamilton, Ontario, May 27, 2000; Annual Community Meeting, The University of Western Ontario, London Convention Centre, London, Ontario, March 30, 2000; Communication in Medicine Conference, Northwestern University, Chicago, Illinois, July 1999; Reasons for Hope, National Scientific Conference, CBCRI, Toronto, Ontario, June 1999; North American Primary Care Research Group Annual Meeting, Montreal, Quebec, November 1998; Trillium Primary Care Research Forum, The University of Western Ontario, London, Ontario. May 30, 1998; Communications Skills Task Force, Cancer Care Ontario, Toronto, Ontario, January 13, 1998; 26th Annual Ontario Occupational Health Nurse's Conference. London, Ontario. October 1997; National Cancer Institute of Canada 50th Anniversary Celebration,Windermere Manor, London, Ontario, October 30, 1996; Communication in Breast Cancer-Forum to develop strategies to enhance Physician-Patient Interaction, Calgary, Aberta, February 11, 1996.

Funding support: This study was funded by the Canadian Breast Cancer Research Initiative of the National Cancer Institute of Canada. Dr. Stewart is funded by the Dr. Brian W. Gilbert Canada Research Chair. The setting of the study was the Thames Valley Family Practice Research Unit, a health systems-linked research unit funded by the Ministry of Health and Long-Term Care of Ontario.

Disclaimer: The views expressed in this paper are those of the authors, and do not necessarily reflect those of the Ministry of Health and LongTerm Care of Ontario.

Acknowledgments: We are grateful for the help of the participating doctors from community family practice in London Ontario and area; the Department of Surgery at The University of Western Ontario, London; the London Regional Cancer Centre; the Hamilton Regional Cancer Centre; and the Toronto-Sunnybrook Regional Cancer Centre. We thank Larry Stitt of the Biostatistical Support Unit; and the Standardized
Patient Program, Schulich School of Medicine and Dentistry. We gratefully acknowledge the wisdom and contribution of breast cancer survivors who served on the Advisory Committee: Louisette Smith, Brenda McKelvey-Donner, Sharron Bearfoot, Anne Buchanan, Sandy Krueger, Barb Barton-McMillan, Veronica Dryden, Margie McPhillips, Barbara Garvin, Addie Gushue, and Katherine DeCaluwe.

\section{References}

1. Lerman C, Daly M, Walsh WP, et al. Communication between patients with breast cancer and health care providers. Determinants and implications. Cancer. 1993;72(9):2612-2620.

2. Ford S, Fallowfield L, Lewis S. Can oncologists detect distress in their out-patients and how satisfied are they with their performance during bad news consultations? Br J Cancer. 1994;70(4):767-770.

3. Hall JA, Dornan MC. Meta-analysis of satisfaction with medical care: description of research domain and analysis of overall satisfaction levels. Soc Sci Med. 1988;27(6):637-644.

4. Golin CE, DiMatteo MR, Gelberg L. The role of patient participation in the doctor visit. Implications for adherence to diabetes care. Diabetes Care. 1996;19(10):1153-1164.

5. Stewart MA. Effective physician-patient communication and health outcomes: a review. CMAJ. 1995;152(9):1423-1433.

6. Levinson W, Roter D. The effects of two continuing medical education programs on communication skills of practicing primary care physicians. J Gen Intern Med. 1993;8(6):318-324.

7. Levinson W, Roter DL, Mullooly JP, Dull VT, Frankel RM. Physician-patient communication. The relationship with malpractice claims among primary care physicians and surgeons. JAMA. 1997;277(7):553-559.

8. Brown JB, Handfield-Jones R, Rainsberry P, Brailovsky CA. Certification examination of the College of Family Physicians of Canada. Part 4: Simulated office orals. Can Fam Physician. 1996;42:1539$1542,1545,1547-1538$.

9. Smith RC, Lyles JS, Mettler J, et al. The effectiveness of intensive training for residents in interviewing. A randomized, controlled study. Ann Intern Med. 1998;128(2):118-126.

10. Tate P, Foulkes J, Neighbour R, Campion P, Field S. Assessing physicians' interpersonal skills via videotaped encounters: a new approach for the Royal College of General Practitioners Membership examination. J Health Commun. 1999;4(2):143-152.

11. Fallowfield L, Hall A, Maguire GP, Baum M. Psychological outcomes in women with early breast cancer. BMJ. 1990;301(6765):1394.

12. Keller V, White M. Choices and changes: A new model for influencing patient health behavior. J Clin Outcomes Manag. 1997;4(6):33-36.

13. Fallowfield L, Lipkin $M$, Hall A. Teaching senior oncologists communication skills: results from phase I of a comprehensive longitudinal program in the United Kingdom. J Clin Oncol. 1998;16(5):1961-1968.

14. Baile WF, Kudelka AP, Beale EA, et al. Communication skills training in oncology. Description and preliminary outcomes of workshops on breaking bad news and managing patient reactions to illness. Cancer. 1999;86(5):887-897.

15. Fallowfield L, Jenkins V, Farewell V, Saul J, Duffy A, Eves R. Efficacy of a Cancer Research UK communication skills training model for oncologists: a randomised controlled trial. Lancet. 2002;359(9307):650-656.

16. Roter DL, Hall JA, Kern DE, Barker LR, Cole KA, Roca RP. Improving physicians' interviewing skills and reducing patients' emotional distress. A randomized clinical trial. Arch Intern Med. 1995;155(17):1877-1884.

17. Griffin SJ, Kinmonth AL, Veltman MW, Gillard S, Grant J, Stewart $M$. Effect on health-related outcomes of interventions to alter the interaction between patients and practitioners: a systematic review of trials. Ann Fam Med. 2004;2(6):595-608. 
18. Davis D, O'Brien MA, Freemantle N, Wolf FM, Mazmanian P, Taylor-Vaisey A. Impact of formal continuing medical education: do conferences, workshops, rounds, and other traditional continuing education activities change physician behavior or health care outcomes? JAMA. 1999;282(9):867-874.

19. Mead N, Bower P. Patient-centredness: a conceptual framework and review of the empirical literature. Soc Sci Med. 2000;51(7): 1087-1110.

20. Borgiel AE, Williams JI, Davis DA, et al. Evaluating the effectiveness of 2 educational interventions in family practice. CMAJ. 1999;161(8):965-970.

21. McWilliam CL, Brown JB, Stewart M. Breast cancer patients' experiences of patient-doctor communication: a working relationship. Patient Educ Couns. 2000;39(2-3):191-204.

22. Stewart M, Brown J, Weston W, McWhinney I, McWilliam C, Freeman T. Patient-Centered Medicine: Transforming the Clinical Method. 2nd ed. Oxford UK: Radcliffe Medical Press Ltd; 2003.

23. Merriam S, Cunningham P, eds. Handbook of Adult and Continuing Education. San Francisco, Calif: Jossey-Bass; 1989.

24. Merriam S, Caffarella R, eds. Learning in Adulthood. San Francisco, Calif: Jossey-Bass; 1991.

25. Schon D. The Reflective Practitioner: How Professionals Think in Action. New York, NY: Basic Books; 1983.

26. Schon D. Educating the Reflective Practitioner. San Francisco, Calif: Jossey-Bass; 1987.

27. Kolb D. Experiential Learning: Experience as the Source of Learning and Development. Upper Saddle River, NJ: Prentice-Hall; 1984.

28. Polanyi M. Personal Knowledge: Towards a Post-Critical Philosophy. Chicago, Ill: The University of Chicago Press; 1958.

29. Patton M. Qualitative Evaluation and Research Methods. 2nd ed. Thousand Oaks, Calif: Sage Publications; 1990.

30. Guba E, Lincoln Y. Fourth Generation Evaluation. Newbury Park, Calif: Sage Publications; 1989.

31. Brown J, Stewart M, \& Tessier, S. Assessing Communication between Patients and Doctors: A Manual for Scoring Patient-Centred Communication. London: Centre for Studies in Family Medicine and Thames Val ley Family Practice Research Unit; 1995. Working Paper Series 95-2.
32. Stewart M, Brown J, Levenstein J, McCracken E, McWhinney IR. The patient-centred clinical method. 3. Changes in residents' performance over two months of training. Fam Pract. 1986;3(3):164-167.

33. Stewart M, Brown JB, Donner A, et al. The impact of patient-centered care on outcomes. J Fam Pract. 2000;49(9):796-804.

34. Henbest RJ, Stewart M. Patient-centredness in the consultation. 2: Does it really make a difference? Fam Pract. 1990;7(1):28-33.

35. Roberts CS, Cox CE, Reintgen DS, Baile WF, Gibertini M. Influence of physician communication on newly diagnosed breast patients' psychologic adjustment and decision-making. Cancer. 1994;74(1 Suppl):336-341.

36. Derogatis L. SCL-90 (R): Administration, Scoring and Procedures Manual-I for the Revised Version of Other Instruments of the Psychopathology Rating Scale Series. Baltimore, Md: Clinical Psychometrics Research Unit, John Hopkins University of Medicine; 1977.

37. Henbest R. A Study of the Patient-Centred Approach in Family Practice. Ontario, Canada: The University of Western Ontario; 1985.

38. Hulley S, Cummings S. Designing Clinical Research. Baltimore, Md: Williams and Wilkins; 1988.

39. Donner A, Klar N. Design and Analysis of Cluster Randomization Trials in Health Research. London, UK: Arnold; 2000.

40. Carney PA, Dietrich AJ, Eliassen MS, Owen M, Badger LW. Recog nizing and managing depression in primary care: a standardized patient study. J Fam Pract. 1999;48(12):965-972.

41. Hutchison B, Woodward CA, Norman GR, Abelson J, Brown JA. Provision of preventive care to unannounced standardized patients. CMAJ. 1998;158(2):185-193.

42. Epstein RM, Franks P, Shields CG, et al. Patient-centered communication and diagnostic testing. Ann Fam Med. 2005;3(5):415-421.

43. Korsch BM, Gozzi EK, Francis V. Gaps in doctor-patient communication. 1. Doctor-patient interaction and patient satisfaction. Pediatrics. 1968;42(5):855-871. 